\title{
Heterogeneidade mostrada em propagandas eleitorais no rádio para o Plebiscito 2011
}

\section{Shown heterogeneity in election advertisements on the radio for the 2011 Plebiscite}

\author{
Flávia Marinho LISBÔA \\ Universidade Federal do Sul e Sudeste do Pará (UNIFESSPA) \\ Hildete Pereira DOS ANJOS \\ Universidade Federal do Sul e Sudeste do Pará (UNIFESSPA)
}

\begin{abstract}
RESUMO: Este trabalho tem como objetivo refletir sobre as propagandas eleitorais veiculadas no rádio durante o período de campanha eleitoral do plebiscito para a consulta sobre divisão do estado do Pará, ocorrido em dezembro de 2011. Para tal reflexão tomou-se como dispositivo teórico-analítico o conceito de heterogeneidade mostrada (Authier-Revuz). As análises encontram, nas marcas discursivas relacionadas a endereçamento e antecipação, categorias próprias do conceito de heterogeneidade mostrada, a escolha de determinados referentes (finanças, dimensão territorial, unidade cultural), descrição dos embates socioculturais em termos de polarização simples (sim/não) e os interlocutores descritos como sujeitos do próprio discurso, o qual redimensiona os referentes ao produzir efeitos de sentido ancorados nessa polarização.
\end{abstract}

PALAVRAS-CHAVE: Plebiscito. Propaganda Eleitoral. Análise do Discurso. Heterogeneidade Mostrada.

ABSTRACT: This paper is a reflection about electioneering aired on the radio during the political campaign for the plebiscite for consultation on the state of Pará division, held on December 2011. For such reflection it was taken as a theoretical and analytical device the concept of shown heterogeneity (Authier-Revuz). The analyzes are in the discursive marks related to addressing and anticipation own categories describing shown heterogeneity, the choice of certain related (finance, territorial dimension, cultural unity ), description of sociocultural conflicts in terms of simple polarization ( yes / no) and the parties described as subjects of discourse itself, which resizes those relating to the effect of meaning anchored in this polarization.

KEY-WORDS: Plebiscite. Electoral Advertisement. Discourse Analysis. Shown heterogeneity.

\section{Introdução}

Este artigo tem origem na dissertação de uma das autoras ${ }^{1}$, a qual analisa estratégias discursivas presentes nas propagandas eleitorais veiculadas no rádio durante

\footnotetext{
1 A dissertação de Flávia Marinho Lisbôa se intitulou "Sim e Não: Formações Discursivas e Ideológicas em propagandas eleitorais radiofônicas do plebiscito para divisão do Pará em 2011". Orientada por Hildete Pereira dos Anjos, foi defendida em março de 2014 pelo Programa de PósGraduação em Dinâmicas Territoriais e Sociedade na Amazônia, da Universidade Federal do Sul e Sudeste do Pará (UNIFESSPA).
} 
o plebiscito para a consulta sobre a divisão do estado do Pará, visando à criação dos estados de Carajás e Tapajós, plebiscito esse ocorrido em dezembro de $2011^{2}$. Apesar da consulta popular ter tratado da possibilidade de criação de dois estados, a pesquisa que levou à dissertação se limitou a analisar as propagandas de rádio que foram difundidas na região sul e sudeste do Pará (região que, do ponto de vista geográfico, pertenceria ao estado de Carajás, a ser criado).

Encontramos poucos trabalhos que tratam das relações entre política, discurso e rádio, ao contrário da televisão, que tem sido regularmente objeto de estudo em trabalhos de análises linguísticas. Este estudo vem, portanto, se juntar à pouca bibliografia existente acerca de discursos radiofônicos no Horário Gratuito de Propaganda Eleitoral (daqui em diante referido como HGPE). Foram analisadas vinhetas de rádio dos dois comitês em enfrentamento: um a favor da Divisão (o Sim) e outro contra (o Não). Sendo o material analisado fruto de uma disputa eleitoral, a ideia com que trabalhamos é a de que os discursos das propagandas dos dois comitês para o Plebiscito 2011 precisam utilizar estratégias discursivas que desconstroem o discurso rival. Para tanto, pautamo-nos no conceito de heterogeneidade mostrada, de AuthierRevuz (2011), para mostrar, do ponto de vista discursivo, como se configuram tais estratégias.

\section{Plebiscito 2011: contextualização sociohistórica}

Em uma análise discursiva, deve-se considerar que os discursos não são produzidos fora de uma ordem sociohistórica, que dá condições à produção de sentidos, o que é corroborado por De Certeau (1995, p. 23).

a análise dos antecedentes, dos quais o discurso não fala, permitirá precisar as leis silenciosas que circunscrevem o espaço da operação histórica. A historicidade do texto, ou seja, sua discursividade (sua determinação histórica) não é mero reflexo do exterior, mas se constitui na própria tessitura da materialidade lingüística. Um texto histórico enuncia uma operação que se situa no interior de um conjunto de práticas.

A partir dessa premissa, remontamos resumidamente neste tópico os antecedentes sociohistóricos aos discursos das propagandas eleitorais das quais tratam as análises desse artigo.

A expansão do capital na Amazônia é responsável pelo início de uma acelerada migração de todo o Brasil para as regiões sul e sudeste do Pará, que até hoje é incessante pelos recorrentes projetos de grandes proporções que se instalam ao longo da história da região, projetos esses que têm seus interesses priorizados pelo Estado em detrimento dos direitos de comunidades tradicionais e da população local como um

\footnotetext{
${ }^{2}$ Tratamos aqui da propaganda plebiscitária veiculada no horário gratuito do rádio. A normatização das veiculações foi feita pelo Tribunal Superior Eleitoral, por meio da Resolução $n^{0} 23.354$, que definiu a exibição da propaganda gratuita nos meios de comunicação, entre 11.11.2011 a 07.12.2011. No rádio a exibição das propagandas plebiscitárias foi feita em blocos das $7 \mathrm{~h}$ às $7 \mathrm{~h} 10$ e das $12 \mathrm{~h}$ às $12 \mathrm{~h} 10$, e foram veiculadas às segundas, terças, quartas e sextas-feiras e aos sábados. O plebiscito para consulta sobre divisão do Estado do Pará para a criação do Estado do Carajás e do Estado do Tapajós, realizado em dezembro de 2011, foi convocado por meio dos Decretos Legislativos n 136/2011 e n 137/2011.
} 
todo, fomentando a reclamação da falta de investimentos básicos que garantam melhor qualidade de vida.

Nesse cenário de tantos conflitos de interesses, ocasionados por uma política desenvolvimentista (marcado por constantes investidas do grande capital), outro projeto, desta vez político, passa a fazer parte da pauta de reivindicação das classes hegemônicas da região, que é o desligamento do sul e sudeste paraense do restante do Pará para ser criado um novo estado: o Carajás.

De acordo com a bibliografia disponível, esse projeto de divisão foi arquitetado pelo professor José da Silva Brandão, que, em 1981, iniciou por conta própria estudos de viabilidade para a criação do Carajás, a partir do desmembramento das regiões sul e sudeste do restante do Pará. Em dezembro de 1988 o projeto foi divulgado na imprensa e a partir de então foi iniciada uma luta pela emancipação regional, levada adiante pelos políticos dos municípios que comporiam essa nova conformação territorial e financiada pelos empresários da mesma região.

A Comissão Brandão relata que a partir desse momento, em que o projeto caiu em domínio público, a proposta não só teve a aceitação dos moradores da região como também se tornou o desejo dessa população. Um exemplo de que a inculcação do projeto no povo teve êxito é que quem se manifestasse, na região de Sul/Sudeste do Pará, contrário à divisão sofria retaliações. Isso desde tempos de quando o projeto começou a ganhar força até no período do plebiscito. Para exemplificar, temos o exemplo do sociólogo Ribamar Ribeiro Junior, que se manifestou contrário à divisão em reportagem veiculada no Jornal Nacional, da Rede Globo, no período de campanha do plebiscito. (LISBÔA, 2014, p. 55).

Ao longo de trinta anos circula nos espaços regionais a proposta de divisão como a solução para os problemas sociais locais, especialmente os de infraestrutura, o que fortalece o sonho de progresso e desenvolvimento compartilhado entre os moradores da região. Enquanto o movimento separatista é lentamente gestado durante esse longo período, por outro lado as manifestações contrárias à divisão não se estabelecem enquanto um movimento contínuo (como ocorre na região que pleiteia o Carajás), mas surge apenas nos momentos críticos em que a proposta de divisão toma maiores repercussões, opondo-se à divisão com posicionamento de que a parte rica do estado não pode ser entregue aos forasteiros ${ }^{3}$, referindo-se ao fato de que a região é maciçamente composta por pessoas que migraram de outras regiões do país.

As mobilizações na região foram providenciais para repercutir no Estado e até mesmo no Brasil a importância do projeto, que voltou a figurar espaço de destaque na imprensa e nos debates cotidianos da população. Como medidas estratégicas para a aprovação do projeto, a Comissão Brandão participou em Brasília, no Congresso Nacional, das plenárias, lobbies e outras articulações em parceria com a AMAT, prefeitos, vereadores e simpatizantes da causa.

Na Câmara Federal, como Projeto de Decreto Legislativo $n^{\circ} 2.300$, o projeto foi homologado, o que permitiu a realização do Plebiscito ocorrido em 11 de dezembro de 2011. Nesta data, a população foi interpelada, por meio de uma eleição, se dizia Sim ou Não para a divisão do estado do Pará para a criação dos estados de Carajás e Tapajós.

3 Sobre esse aspecto ver LISBOA; ANJOS (2016). 
os eleitores do sul e sudeste do Pará foram $93,87 \%$ a favor da criação do Carajás, enquanto apenas $6,13 \%$ se opuseram. Porém, a criação não foi possível porque mais de $94 \%$ do eleitorado que corresponderia ao novo estado do Pará votou contra, considerando-se que o número de eleitores dessa região é bem maior que a do pretenso estado de Carajás . Não satisfeita com o resultado, no dia seguinte (12/12/2011), no grupo RBA/Marabá (usando as emissoras de tevê e rádio), a Comissão Brandão lançou o Projeto de Lei de Iniciativa Popular (PLIP) e, tão logo, iniciou a coleta de assinaturas de eleitores favoráveis à divisão. No ano seguinte, a Prefeitura Municipal de Marabá, o deputado federal Asdrúbal Mendes Bentes (PMDB), a deputada estadual Bernadete tem Caten (PT) e a Comissão Brandão deram entrada em Ação Rescisória, da Ação Direta de Inconstitucionalidade (ADIN) 2650, no Supremo Tribunal Federal, contra o presidente da República Federativa do Brasil e o Congresso Nacional por, segundo eles, violarem dispositivos constitucionais, já que, no entendimento dos requerentes, em termos gerais, os requeridos não permitiram a delimitação da votação do plebiscito apenas nas regiões que propuseram a criação de novos estados. (LISBÔA, 2014, p. 66).

Com essa Ação Recisória, a intenção é que uma nova consulta popular seja feita, mas com a participação de todos os eleitores do território nacional e não apenas nas regiões diretamente afetadas pela divisão.

O trabalho de que trata este artigo enfoca um dos aspectos discursivos do plebiscito, que foi a produção de vinhetas de rádio por ambos os comitês; polemizando determinados referentes e silenciando outros, evocando enunciados contrários para produzir argumentação, antecipando possibilidades enunciativas, endereçando sua elaboração discursiva ao eleitor ou ao comitê contrário, a produção dos dois comitês traz a heterogeneidade discursiva em sua forma marcada, ao mesmo tempo em que evoca a memória dos enfrentamentos eleitorais, constitutiva desse modo de produzir discurso.

\section{Dispositivo teórico-analítico: heterogeneidade mostrada}

Como afirma Pechêux (2010), discurso, sujeito e ideologia são noções imbricadas: não se pode considerar a existência de um discurso sem sujeito, mas também não há sujeito sem ideologia: esta é que interpela o indivíduo em sujeito. Partimos dessa afirmação para pautar nosso estudo na premissa de que os sujeitos dos discursos ocupam posições sociais e históricas, sendo elas responsáveis por condicionar as produções discursivas. O sujeito, aqui, é concebido como clivado pelas ideologias, que limitam os discursos possíveis em determinada conformação social; a produção desses discursos sempre leva em consideração também o outro, como interlocutor nesse jogo de interação verbal, que sempre será constituído por discursos heterogêneos, de forma mostrada (marcada no texto) ou de forma constitutiva, conforme Authier-Revuz (2011).

Segundo Bakhtin, “[...] toda palavra comporta duas faces. Ela é determinada tanto pelo fato de que procede de alguém como pelo fato de que se dirige para alguém. 
Ela constitui justamente o produto da interação do locutor e do ouvinte [...]" (BAKHTIN, 1997, p. 113). Entendendo que o dizer é não apenas permeado por outras vozes, mas determinado por tal processo interativo, Authier-Revuz (2011) discute a partir de duas perspectivas essa formação heterogênea dos discursos: [uma] "interdiscursiva, de um lado, com a exterioridade do meio do já-dito dos outros discursos"[outra]; "interlocutiva, de outro lado, com esse outro dizer específico de - ou emprestado a - aquele a quem alguém se dirige". (AUTHIER-REVUZ, 2011, p. 7).

A primeira perspectiva é tratada pela autora como heterogeneidade constitutiva, conceito através do qual Authier-Revuz se refere às relações entre as noções de dialogismo, em Bakhtin e interdiscurso, em Pêcheux: "a presença permanente, profunda, de 'outros lugares', do 'já dito' dos outros discursos condicionando todas as nossas palavras e ressoando nelas" (1998, p. 135).

Todo dizer, e incessantemente, não pode não ser habitadodeterminado-dividido-etc. pela realidade da exterioridade discursiva na qual ele se produz, e se recebe, que remete, como constitutiva, a não-coincidência do discurso com ele próprio (ou sua heterogeneidade discursiva constitutiva) (AUTHIER-REVUZ, 2011, p.8)

Já a heterogeneidade interlocutiva, também tratada pela autora como "mostrada" (por ser mais evidente na materialidade do texto), de acordo com a autora, "é um conjunto de formas [que inscrevem] o outro na sequência do discurso - discurso direto, aspas, formas de retoque ou de glosa, discurso indireto livre, ironia[...]" (1990, p.25).

A partir dessa segunda noção de heterogeneidade, analisamos o corpus buscando o funcionamento dos discursos das propagandas, evidenciando que, no corpus composto por textos assumidos pelos dois comitês (as vinhetas de propaganda eleitoral) existe uma heterogeneidade cujas marcas são explícitas; tais marcas mostram a presença, no texto de cada vinheta, do discurso concorrente, evocado como estratégia para desconstruir as verdades que o outro defende. Apoiar-nos-emos, então, no conceito de heterogeneidade interlocutiva para a análise dos dados, partindo, para isso, das noções de endereçamento e antecipação, a seguir definidas por Authier-Revuz (2011, p.7):

(1) não há discurso que não seja endereçado. A dimensão do endereço encarna-se certamente de modo diferente segundo as condições concretas do dizer - do diálogo ao jornal íntimo - mas ela é inerente ao dizer; o dizer "não endereçado" é ficção.

(2) O dizer do um é, de modo constitutivo, determinado, atravessado, penetrado pelo pensamento do dizer do outro - destinatário. Para o círculo de Bakhtin, é pelo mecanismo, inerente ao dizer, de antecipação da "compreensão responsiva" do destinatário que passa esse segundo eixo - interlocutiva - do dialogismo. (AUTHIERREVUZ, 2011, p. 7).

As formas marcadas da heterogeneidade discursiva têm, diz a autora, um modo próprio de operar: a denegação da heterogeneidade constitutiva, "por uma espécie de compromisso precário que dá lugar ao heterogêneo e portanto o reconhece mas para negar sua onipresença. Elas manifestam a realidade desta onipresença precisamente nos lugares que tentam encobri-la" (AUTHIER-REVUZ,1990, p.33). Assumindo esse ponto de vista, abordaremos as vinhetas de rádio através de um dispositivo teórico-analítico que recorta, na materialidade do texto, a presença do outro imediato (o comitê 
concorrente), evidenciando endereçamentos e antecipações. Não perderemos de vista, no entanto, o interdiscurso como o Outro, aquele que é denegado na alternância discursiva que parece atribuir a locutores distintos um discurso que atravessa, pelas condições de produção comuns a ambos os comitês, o movimento dialógico.

Analisar a heterogeneidade marcada como denegação da heterogeneidade constitutiva (considerando que a denegação em que se marca o outro no discurso produz um efeito de que cada produção discursiva tem um autor consciente, escamoteando o fato de que os discursos são constitutivamente heterogêneos) implica considerar duas noções básicas ao tratar o texto: condições de produção do discurso e efeitos de sentido. O último conceito é objeto de uma "breve cartografia" realizada por Baronas (2005, p. 1), o qual afirma que tal noção "está ligada umbilicalmente desde a sua gênese à noção de discurso", já que esta não admite um sentido em si mesmo.

Diz Orlandi (2007, p. 21) a esse respeito:

Compreender o que é efeito de sentido, em suma, é compreender a necessidade da ideologia na constituição dos sentidos e dos sujeitos. É da relação regulada historicamente entre as muitas formações discursivas (com seus muitos sentidos possíveis que se delimitam reciprocamente) que se constituem os diferentes efeitos de sentido entre locutores. Sem esquecer que os próprios locutores (posições do sujeito) não são anteriores à constituição desses efeitos mas se produzem com eles.

Para entender essa última frase no texto de Orlandi, é importante lembrar que a noção de ideologia se modifica ao longo do trabalho de Pêcheux. Retomando Baronas, a posição pecheutiana acerca do sentido vai se modificando: se no livro "Semântica e discurso: uma crítica à afirmação do óbvio" o autor defende que ele "é determinado pelas posições ideológicas que estão em jogo no processo sócio-histórico no qual as palavras, expressões e proposições são produzidas (isto é, reproduzidas)", em seu último livro, "Discurso: estrutura ou acontecimento?" Pêcheux incorpora a noção de equívoco "como constitutivo da língua [...] não existe ritual sem falha" (2005, p. 3). Desse modo, as posições ideológicas atravessam a produção do sentido, mas como condição de possibilidade, não como determinação: o acontecimento discursivo faz com que os sentidos derivem para outros, e é aí que se situa o trabalho da interpretação. Ao trabalhar com as marcas do outro no texto, mobilizamos, portanto, sentidos para além do enunciado, sentidos já produzidos acerca da região, do eleitorado, da formatação dos comitês, de seus posicionamentos ideológicos; mobilizamos também, sentidos derivados da formatação textual (vinhetas de rádio), do acontecimento (plebiscito), das temáticas mobilizadas ou silenciadas nesse processo.

A noção de condições de produção do discurso se articula àquela de efeitos de sentido, na medida em que a consideramos, com Pêcheux, não a produção específica e imediata das vinhetas para a propaganda, mas a materialidade histórica na qual tal produção faz sentido: 
Ao mobilizar a noção de condições de produção do discurso, explicitamos que, na base dos processos discursivos, além da materialidade simbólica, há também uma materialidade histórica, formada pelas relações sociais de uma determinada formação social, em meio às quais (e para as quais) os sujeitos históricos trabalham a formulação dos "seus" dizeres, provocando agitações nas filiações dos sentidos e, também, como aqui é proposto, produzindo uma práxis discursiva (FONSECA, 2010, p.3)

O esforço interpretativo não está isento, é claro, da imbricação de quem pesquisa nas mesmas condições de produção, considerando que o acontecimento é recente (se deu em 2011) e as pesquisadoras atuam na mesma região em que ele ocorreu, tendo tomado posição a respeito, na qualidade de eleitoras. Porém, quando interpretamos, nós o fazemos a partir de marcas que estão no texto; os sentidos evocados por tais marcas escapam à subjetividade individual por se inscrever concomitantemente na história e na língua:

Se os enfeixamentos, tanto das temáticas quanto dos modos de operar, são feitos 'de fora', por quem está na posição de pesquisador, não são feitos da forma exigida pelos desejos de quem pesquisa. Não há que negar que eles só podem ser feitos porque algo nas configurações dos efeitos de sentido os 'atrai' para uma mesma 'rede semântica' e isso certamente tem relação com as posições daquele modo de operar, temática ou gênero de discurso no campo relacional (ANJOS, 2015, p. 121).

Assim, ressaltamos que o recorte das vinhetas e a interpretação do funcionamento dos discursos são desdobramentos que, ainda que partam da prática do analista (também discursiva), só foram possíveis pelas relações que os discursos mantêm com suas condições de produção (entendendo o interdiscurso como parte de tais condições).

\section{O trabalho analítico com o texto das vinhetas}

Tratando-se de um enfrentamento político, portanto de um discurso polêmico (ORLANDI, 2003), as produções discursivas de um comitê precisam se referir às do outro, porque é através dessa memória que o discurso trabalhará na desconstrução dos efeitos de sentido que a produção rival pretendeu instaurar. As produções verbais são intencionalmente construídas para responder, refutar às argumentações do concorrente político. "Em alguns casos, o texto é praticamente o mesmo, alternando apenas as posições que os comitês ocupam como locutor e interlocutor do discurso" (LISBÔA e ANJOS, 2015, p. 73-74).

Por meio de elementos textuais, a análise discursiva buscou apreender possíveis efeitos de sentidos criados pelos mecanismos de endereçamento e antecipação, próprios 
da heterogeneidade que se apresenta de forma marcada ${ }^{4}$. O trabalho interpretativo procurou destacar, através de tais mecanismos, a mobilização de determinados sentidos (e o consequente ocultamento de outros), a retomada dos sentidos mobilizados pelo comitê rival e a seleção da produção discursiva digna de réplica.

Para tal empreitada, trazemos a transcrição de seis vinhetas ${ }^{5}$ para análise, as quais apresentamos e discutimos a seguir.

(1): $\underline{O}$ não afirma que o Pará perde com a divisão. Isso não é verdade. $O$ governo do Pará recebe hoje do Fundo de Participação dos Estados, do governo federal, $R \$ 2,9$ bilhões/ano. Depois da divisão passa a receber $R \$ 5,9$ bilhões, porque passa a ser três estados. São três bilhões a mais por ano. E atenção! Esses dados são oficiais. Se é bom para todo mundo, por que dizer não?

(2): Os separatistas tentam enganar você, dizendo que a divisão do Pará vai melhorar a vida das pessoas mais pobres. Falam em 12 bilhões como se em um passe de mágica o Pará dividido passasse a ter mais recursos quando na verdade terá é mais despesas. A lei é clara. O Pará recebe 6,1\% do FPE. Isto é o que está valendo. Se dividir esse dinheiro, que já é pouco, pelos três novos estados, o que vai aumentar é a pobreza. Pior que querer dividir o Pará é mentir pro povo do Pará. Vote 55, contra a criação de Carajás.

As marcas discursivas da heterogeneidade mostrada são pautadas, nas vinhetas (1) e (2), pelo discurso indireto, senão vejamos: (1) "O não afirma que [...]; (2) Os separatistas tentam enganar você, dizendo que [...]. O uso dessa forma textual é acompanhado por sua negação, expressa em (1) "Isso não é verdade" e em (2) "tentam enganar você".

$\mathrm{Na}$ continuidade da primeira vinheta, produzida a fala do outro como inverdade, o locutor apresenta sua própria verdade: intenta convencer os eleitores da capital, Belém, a votar no Sim com o argumento de que os recursos do Fundo de Participação dos Estados aumentariam com a divisão, comparando com o que era repassado ao Pará na época; o aumento significaria três bilhões de reais a mais por ano, o que beneficiaria o Pará e também os dois novos estados. Para dar status de verdade à informação, recorre ao argumento da autoridade, enfatizando de onde partem as informações, de quem é autorizado a falar sobre o assunto: "esses dados são oficiais". Em (2), em contrapartida, o Não desmoraliza o Sim quanto à informação utilizada: "tentam enganar você"/ "pior que querer dividir o Pará é mentir pro povo do Pará". As duas vinhetas abordam o mesmo referente (recursos que seriam repassados pelo Fundo de Participação dos Estados). Cada uma o faz de modo a parecer informativa (trazendo dados do campo da economia e do direito, portanto socialmente referendados) e a caracterizar o outro como pouco informado ou mal intencionado. Em (1) o Não argumenta que as contas que o Sim faz não condizem com a realidade, concluindo que "o que vai aumentar é a

\footnotetext{
Para este trabalho, para atender às normas da revista, numeramos as vinhetas sequencialmente e nos referimos a elas por sua numeração no interior do texto.

$5 \quad$ Neste artigo analisamos apenas o texto transcrito, sob o aspecto da heterogeneidade marcada. Em outro trabalho (LISBÔA, ANJOS e RIBEIRO, 2015) nos dedicamos às vinhetas de rádio com uma análise mais ampla, enfocando também os aspectos sonoros na tentativa de dar conta dos efeitos de sentido gerados pela materialidade radiofônica.
} 
pobreza". Por fim, a vinheta é encerrada do mesmo jeito que começou, chamando o comitê adversário de mentiroso. Em (2) o rival é nomeadamente marcado no discurso também logo no início do texto: "O não afirma que o Pará perde com a divisão. Isso não é verdade". Esse início da vinheta é o resumo de como a propaganda é construída de forma geral, pois a partir desse trecho inicial o que acontece ao longo da vinheta é a desconstrução do sentido de que o Pará perderia com a divisão, sentido produzido pelo discurso em (1). Assim como na primeira sentença, as demais dão continuidade ao trabalho de reforçar a argumentação de que o Não mente. Após evocar o rival, o trabalho discursivo é focado em desmenti-lo.

Desta forma, cada comitê precisa se referir ao outro como "senhor e fonte do seu dizer" (Authier- Revuz, 1990, p.26): ambas as frentes políticas estruturam suas vinhetas da mesma forma, trazendo o comitê concorrente de forma marcada ("O não" / "Os separatistas") no início do texto e em seguida o desqualificando, seja pelo adjetivo "separatistas", carregado semanticamente pelo já-dito da importância da unidade territorial, seja pela caracterização da fala do outro como mentirosa (tanto o estabelecimento de verdades como de mentiras exigem a intenção e a consciência do sujeito que fala como referência, seja ele indivíduo, grupo social ou instituição).

Outra marca comum das vinhetas é o duplo endereçamento do texto: dirige-se ao eleitor diretamente (através do uso do pronome "você" ou do imperativo "vote 55") ou indiretamente ("porque dizer não?"); dirige-se, ao adversário trazendo-o para a própria fala e desqualificando suas informações.

As vinhetas a seguir, (3) e (4), trazem como referente o tamanho do Pará, outro dos argumentos importantes no embate plebiscitário. Como um dos argumentos recorrentemente retomado pelo Não é o de que o Pará ficaria pequeno com a divisão do território, o Sim produz deslizamentos de sentido em torno da palavra "tamanho", deslocando-a da questão territorial para aspectos da subjetividade do eleitor:

(3): Uma das principais discussões desse plebiscito é a seguinte: o que é mais importante? O tamanho do Pará ou o tamanho do sofrimento do povo do Pará? Para o não o mais importante é o tamanho do Pará, para o sim o mais importante é o tamanho do sofrimento do povo do Pará. E pra você? O que é mais importante? Quem ama cuida, protege, ajuda. Diga sim pro Carajás! Sim!

O sentido que a vinheta (3) busca instaurar é o de que o Não valoriza algo (o tamanho do Pará) que não fará diferença para resolver os problemas ou o sofrimento do povo do Pará. A marca da heterogeneidade se evidencia nas expressões "Para o Não...", com a qual o Sim não apenas parafraseia o Não, mas redimensiona o debate acerca do tamanho do território. Antecipa e desconstrói a preocupação com a diminuição territorial pela estratégia do apelo subjetivo: "sofrimento do povo"/“Quem ama cuida, protege, ajuda". O eleitor é interpelado pelas consequências de seu voto; os efeitos de sentido mobilizados são a possibilidade de que o Sim faça algo pelo sofrimento dos paraenses (em caso de vitória) ou que seja preservado o tamanho do Pará, em detrimento da superação de tal sofrimento.

Na vinheta (4), do comitê do Não, a questão do tamanho também desliza da questão puramente territorial e ganha proximidade semântica com a da integridade cultural. 
(4): Querem tirar 83\% das terras do Pará. É igual tirar do tacacá, os camarões, o jambú, o tucupi e até a goma. Só ia sobrar a cuia. Agora diga: Dá para gostar disso? Não e não. Ninguém divide o Pará. Vote 55. Contra a criação de Carajás.

O discurso outro é evocado nesta vinheta pelo sujeito indeterminado (“Querem..”). Através da expressão "é igual” são equiparadas a separação territorial com os ingredientes do tacacá, alimento típico das regiões tradicionais do Pará, mas não necessariamente da região o que seria o estado de Carajás. O endereçamento, aqui, é óbvio: a evocação de uma unidade identitária, baseada numa noção homogênea de cultura, afeta o eleitor da região metropolitana e do norte do estado, mas não aquele do sul e sudeste do Pará, que não tem o tacacá como uma alimentação regular, portanto, como um prato que integre a cultura alimentar regional.

A vinheta (5), do Sim, retoma o tamanho do território como referente e inicia seu texto parafraseando a fala do rival:

(5): Com a divisão, o Pará não vai ficar pequeno demais? Negativo. Tirando as áreas de reserva florestal e indígena do governo federal, os três estados vão ficar praticamente do mesmo tamanho. O que vai diminuir de verdade é o sofrimento do povo do Pará. Diga sim pro Carajás! Sim!

Transformar a afirmação do outro em pergunta coloca em pauta dois possíveis efeitos de sentido. Por um lado, agrega valor positivo à questão: vale a pena retomar a questão do tamanho. Por outro lado, esse valor é rebatido na produção que segue: essa retomada traz novos elementos, importantes para que o eleitor se situe (novamente a vinheta ganha tom informativo). A releitura do espaço territorial é feita "tirando as áreas de reserva florestal e indígena do governo federal". Excluídas do território em disputa, florestas e grupos indígenas não contam na configuração do estado: são atribuídas ao governo federal. $\mathrm{O}$ endereçamento do discurso é feito agora para um eleitor específico: aquele para quem a informação de que florestas e indígenas não contam faz sentido, já que reservas (como o próprio nome sugere) não poderiam ser exploradas, economicamente falando, o que, na construção de sentido da vinheta, se configura em argumento para que não sejam considerados esses espaços de reserva (entendidos como território de ninguém) na composição dos novos estados.

O outro deslizamento de sentido importante para nossa análise é a agregação ao adjetivo "pequeno" do advérbio de intensidade "demais": a discussão não é mais sobre o tamanho do Pará tomado separadamente; trata-se agora de sua comparação com os outros estados a serem criados. O adjetivo "pequeno" incorpora o discurso do outro acerca das perdas territoriais; ao contrário de (3), em que a questão da dimensão do Pará desliza de "território" para "sofrimento", aqui ela não é mais questionada. O texto assume, pelo acréscimo de uma modalização ("demais") a acusação evocado do discurso outro.

Uma última vinheta, (6), traz o referente da unidade, já subjacente aos anteriores (fundo de participação e tamanho do território): 
(6) (Música): Eu digo não e não. Eu digo não e não. Eu digo não e não. Eu quero a união. É isso aí, o meu Pará ninguém divide, irmão. Tanta beleza e riqueza tá na nossa mão. É nosso rio, floresta, nosso minério, então. Tudo da nossa gente. Todos do mesmo chão. Vote 55. Diga não à divisão. Vote 55. Contra a criação de Carajás.

O endereçamento se evidencia por marcas textuais especificas: o vocativo "irmão" e os pronomes possessivos "nossa", "nosso". Em todos os casos, o eleitor que pode votar na opção contrária não é o interlocutor do discurso: esse "irmão" é aquele com quem o locutor compartilha a luta por unidade territorial. A palavra "união", que poderia ser interpretada como a superação da divisão entre pontos distintos, ganha sinonímia com "unidade". A antecipação do pertencimento do interlocutor à mesma ordem discursiva, dada pelas expressões "nossa gente", "nosso chão" reforça esse modo de endereçar. Um silenciamento é evidente em tal ordem discursiva: efeitos de sentido que levassem às noções de divisão de classe, explorados e exploradores, grupos excluídos não cabem. O rio, o minério, a floresta, são referentes que, descritos pela chave da unidade, pertencem a todos ("tudo da nossa gente"). Companhias transnacionais que exploram o minério, processos de destruição da vida nos rios pela implantação de hidrelétricas, territórios indígenas sendo invadidos, alagados, destruídos, florestas devastadas para a plantação de capim para pastos não são assuntos que poderiam produzir os efeitos de sentido desejados, por isso são calados na propaganda.

O outro (o que diz sim) é evocado em (6) pela negação em "o meu Pará ninguém divide". O texto evoca um não-dito: há "ninguéns" querendo dividir um Pará que não é deles: é "meu". O interdiscurso que atravessa esse enunciado traz a imagem do "estrangeiro" que colonizou as regiões sul e sudeste do Pará; aquele que, não sendo paraense, não pode compartilhar a "posse" de rios, minério, floresta. Seria surpreendente a ausência de um outro, os povos indígenas, habitantes nativos, nesse discurso, se este referente também não estivesse relegado ao não-dito por não caber no discurso da unidade: sua evocação incomoda tanto a noção de cultura como coisa homogênea quando a noção de território como espaço do colonizador, como evoca, em (5) a referência às reservas indígenas e florestais.

O trabalho interpretativo, abordando a heterogeneidade evidenciada pelas marcas textuais, mostra modos de endereçamento e antecipação próprios de propagandas eleitorais, as quais precisam considerar os interlocutores como autores, responsáveis pela própria enunciação; precisam sintetizar em verdades curtas os referentes em disputa (território, cultura, finanças), precisam descrever os muitos embates socioculturais em termos dicotômicos. Esse empenho numa descrição simplificada do real encontra amparo no interdiscurso (o discurso Outro que evita o conflito e circunscreve qualquer disputa no campo eleitoral, expressa numa polarização simples: sim e não).

\section{Conclusões}

A heterogeneidade discursiva, conforme Authier-Revuz (1990, 1998, 2011), assume que as vozes em diálogo num texto (Bakhtin, 1999) tem sua produção clivada pela ideologia, entendida aqui tanto como um interdiscurso geral (fala dominante que atravessa todas as outras por tratar cada dito como natural, cujo sentidos estão sob o 
controle de todos), como quer Pecheux em sua produção inicial (1975), quanto pela produção específica nos enfrentamentos datados historicamente, tratada em seus pontos de deriva, como no Pêcheux (2012) dos textos finais.

Os atravessamentos discursivos são evidentes na "seleção" dos referentes: (1) e (2) trazem à baila os debates sobre perdas e ganhos financeiros; (3), (4) e (5) tratam da discussão de perdas em tamanho territorial; (6) apela para a noção de unidade (cultural e territorial). Como tais referentes não se sustentam por si sós (no interdiscurso, não está estabelecido que "todo mundo sabe" dessas coisas), eles ganham novas dimensões semânticas. São associados ao sofrimento popular, às possibilidades de ganhos na economia, à integridade da cultura, à posse das riquezas e belezas naturais por todos (os que defendem a unidade).

O modo marcado como cada interlocutor é trazido pelo outro (pelo discurso indireto, pela paráfrase, pela indeterminação, pelo silenciamento) permite sua desqualificação: a informação dada/retomada é apresentada como falsa, como incompleta, como mal-intencionada. Isso só é possível pela ilusão de que cada locutor é autor consciente do próprio discurso. Poderíamos, no entanto, retomar a noção de heterogeneidade constitutiva para observar que, nas propagandas, um discurso outro atravessa através da ilusão de transparência nos pré-construídos que permitem que os dois comitês dialoguem: a mobilização de temáticas assumidas como importantes para a disputa (finanças, tamanho) e a incorporação/recusa de temáticas que "interpretam" o referente: o sofrimento, a preservação da cultura, as áreas que não contam (reservas florestais e indígenas). A antecipação só é possível pelo conhecimento das redes semânticas comuns entre os dois comitês, por isso os sentidos mobilizados pelas propagandas são: (a) o dinheiro que se perde ou ganha com a divisão do Pará; (b) o tamanho que o estado remanescente terá com a divisão; (c) a unidade cultural/territorial em risco.

Esse movimento interpretativo não se esgota em nosso trabalho, já que novas questões vão surgindo à medida que nos esforçamos por "fechar" a pesquisa. $O$ endereçamento desse debate teria de fato o eleitor como foco? Não se aproxima mais de um diálogo entre pares (que partilham da mesma formação discursiva)? A própria relação subjetiva que se estabelece não seria de intimidade, expressa em fórmulas como "A mente", "B tenta te enganar"? Seriam essas produções discursivas próprias de um enfrentamento político consequente? Que efeitos de sentido se obtém em (5), em que o referente "tamanho" não inclui as reservas florestais e indígenas? São questões que se colocam ao observar como a circulação e o enfrentamento desses discursos produziram, reforçaram e rechaçaram sentidos, de acordo com os interesses em disputa (evidenciados através da heterogeneidade marcada), mas também com os interesses em comum (que se pode perceber levando em conta a heterogeneidade constitutiva). Colocadas à disposição dos analistas de discurso, permitem outros movimentos interpretativos, enriquecendo o campo e abrindo outras chaves de leitura do corpus.

\section{REFERÊNCIAS}

ANJOS, Hildete Pereira dos. Porque a escola não é azul? Os discursos imbricados na questão da inclusão escolar.Jundiaí: Paco Editorial, 2015. 
AUTHIER-REVUZ, Jacqueline. Dizer ao outro no já-dito: interferências de alteridades - interlocutiva e interdiscursiva - no coração do dizer. Letras de Hoje, Porto Alegre, v. 46, n. 1, p. 6-20, jan./mar. 2011.

AUTHIER-REVUZ, Jacqueline. Palavras incertas: as não-coincidências do dizer. Campinas: Editora da Unicamp, 1998.

AUTHIER-REVUZ, Jacqueline. Heterogeneidades Enunciativas. Cad. Est. Ling., Campinas, (19): 25-42, jul/dez, 1990.

BAKHTIN, Mikhail. Marxismo e filosofia da linguagem. $8^{\text {a }}$ ed. São Paulo: Hucitec, 1997.

BARONAS, Roberto Leiser. Efeitos de sentido de pertencimento à análise de discurso. Anais do SEAD Seminários de Estudos em Analise de Discurso, 2005. Disponivel

em http://www.ufrgs.br/analisedodiscurso/anaisdosead/2SEAD/SIMPOSIOS/RobertoLeiser Baronas.pdf > Acesso em 18. Abr. 2016.

DE CERTEAU, Michel. A operação histórica. In: LE GOFF, P.; NORA, P. História. Novos Problemas. Rio de Janeiro: Francisco Alves. 1995.

FONSECA, Rodrigo Oliveira. Condições de produção do discurso e formações discursivas: uma proposta de abordagem da práxis discursiva. Revista Icarahy, Edição n.04 / outubro de 2010. Disponível em http://www.revistaicarahy.uff.br/revista/html/numeros/4/dlingua/Rodrigo_Fonseca.pdf Acesso em Acesso em 18. Abr. 2016.

LISBÔA, Flávia Marinho; ANJOS, Hildete Pereira. Formações discursivas na propaganda eleitoral: o caso do plebiscito para a criação do estado de Carajás. Revista da Anpoll, nº 39, p. 69-79, Florianópolis, Jul./Ago. 2015.

Discurso fundador e território: as regiões do sul e sudeste do Pará narradas nos debates do Plebiscito 2011. In: Tradução e interculturalidade: pontos de convergência. São Paulo: Pedro e João, 2016.

LISBÔA, Flávia Marinho. Sim e Não: formações discursivas e ideológicas em propagandas eleitorais radiofônicas do plebiscito para divisão do Pará em 2011. Dissertação (Mestrado em Dinâmicas Territoriais e Sociedade na Amazônia) Universidade Federal do Sul e Sudeste do Pará, Marabá, 2014.

PÊCHEUX, Michel. O discurso: estrutura ou acontecimento. 6 ed. Traduçãode eni P. Orlandi.Campinas: Pontes, 2012.

PÊCHEUX, Michel. A propósito da análise automática do discurso: atualização e perspectivas (1975). In: GADET, Françoise e HAK, Tony (orgs.). Análise Automática do discurso: uma introdução à obra de Michel Pêcheux. Campinas, SP: Editora da Unicamp, 2010.

ORLANDI, Eni. As formas do silêncio: no movimento dos sentidos. 6 ed. Campinas: Editora da Unicamp, 2007. 
ORLANDI, Eni. A linguagem e seu funcionamento: formas do discurso, São Paulo: Brasiliense, 1983. 